\title{
CONTRACTIBILITY AND ASSET OWNERSHIP: ON-BOARD COMPUTERS AND GOVERNANCE IN U.S. TRUCKING
}

\author{
George P. Baker \\ Thomas N. Hubbard \\ Working Paper 7634 \\ http://www.nber.org/papers/w7634 \\ NATIONAL BUREAU OF ECONOMIC RESEARCH \\ 1050 Massachusetts Avenue \\ Cambridge, MA 02138 \\ April 2000
}

We would like to thank Oliver Hart, Francine Lafontaine, Brian Silverman, Margaret Slade, Jerry Zimmerman, and seminar participants at Carnegie-Mellon, Chicago, Duke, Harvard, Michigan, NBER Summer Institute, Rochester, and Stanford for comments. We also thank Michael Crum and several dispatchers and drivers for useful discussions. We gratefully acknowledge support from NSF grant SES-9975413 and the Harvard Business School Division of Research. The views expressed herein are those of the authors and not necessarily those of the National Bureau of Economic Research.

(C) 2000 by George P. Baker and Thomas N. Hubbard. All rights reserved. Short sections of text, not to exceed two paragraphs, may be quoted without explicit permission provided that full credit, including () notice, is given to the source. 
Contractibility and Asset Ownership: On-Board Computers

and Governance in U.S. Trucking

George P. Baker and Thomas N. Hubbard

NBER Working Paper No. 7634

April 2000

JEL No. L14, L22, L92, D23

\begin{abstract}
We investigate how the contractibility of actions affecting the value of an asset affects asset ownership. We examine this by testing how on-board computer (OBC) adoption affects truck ownership. We develop and test the proposition that adoption should lead to less ownership by drivers, particularly for hauls where drivers have the greatest incentive to drive in non-optimal ways or engage in rent-seeking behavior. We find evidence in favor: OBC adoption leads to less driver ownership, especially for long hauls and hauls that use specialized trailers. We also find that nonowner drivers with OBCs drive better than those without them. These results suggest that technology-enabled increases in contractibility may lead to less independent contracting and larger firms.
\end{abstract}

George P. Baker

Professor of Business Administration

Harvard University

Soldiers Field

Boston, MA 02163

and NBER

gbaker@hbs.edu
Thomas N. Hubbard

Assistant Professor of Economics and Strategy University of Chicago

1101 E. $58^{\text {th }}$ Street

Chicago, IL 60637

and NBER

thomas.hubbard@gsb.uchicago.edu 


\section{Introduction}

What determines who owns assets in the economy? This question, essential to determining the boundary of the firm, goes back at least to Coase (1937), who argued that firms will choose to coordinate activities internally rather than through markets when the cost of transacting in markets is higher than the cost of internal coordination. Transacting in markets is costly, according to Williamson (1975), when contractual incompleteness invites opportunistic behavior. A natural implication of this line of analysis is that improvements in contracting should lead to greater reliance on markets as institutions for mediating economic activity.

Grossman and Hart (1986) caution, however, that the link between improved contracting and increased reliance on market-mediated transactions may not hold. They reinforce the connection between contractual incompleteness and asset ownership by arguing that asset ownership defines the allocation of decision rights that are not specified in existing contracts. ${ }^{1}$ Optimal asset ownership therefore is determined by who most efficiently will hold the residual rights of control. An implication of their theory is that any change in contractibility will induce a new set of noncontractible decision rights, which in turn will force a reevaluation of who should best hold the residual rights of control. How contractibility affects asset ownership and the boundary of the firm thus depends on the details of what becomes contractible, and what remains in the set of residual rights. In this paper, we examine this issue using data from the United States trucking industry.

Nickerson and Silverman (1999) point out that several organizational theorists have cited trucks as "prototypical user-owned assets." ${ }^{2}$ Yet most trucks in the United States, and almost all short-haul trucks, are not owned by their drivers. They are operated by "company drivers"individuals who do not own the trucks they drive-rather than "owner-operators." We argue that ownership patterns in trucking result from the non-contractibility of two sets of decision rights. The importance of each of these sets determines the optimal ownership of trucks. One set of non-

1. There are several possible reasons for contractual incompleteness. Contingencies may be too numerous or uncertain for the parties to specify them ex ante, or outcomes may be too complex or subtle for a third party to verify them ex post. We, along with most papers in this literature, assume that specifying and verifying a particular aspect of a contract is either costless or infinitely costly. In truth, of course, these costs vary over a wide range, and the degree of contractual incompleteness is a choice variable for the parties.

2. Alchian and Demsetz (1972) and Milgrom and Roberts (1992). The latter actually remark in a footnote that monitoring devices have reduced the benefits of driver ownership. 
contractible decision rights is the degree to which drivers engage in rent-seeking activities such as searching for hauls other than those prearranged by carriers. The other set of non-contractible decision rights, at least until the late 1980s, is how drivers operate trucks-in particular, whether they drive trucks in ways that maintain trucks' value.

In the late 1980s, an important technological innovation expanded the set of variables upon which carriers and drivers could contract. The development of on-board computers (OBCs), devices that continuously record various operating parameters of trucks (e.g., their speed), allowed carriers to construct better performance measures of how drivers operate trucks. Our hypothesis is that this change in the contractibility of key decisions should change the optimal ownership of trucks. We propose that it should increase the use of company drivers, especially for hauls where drivers have the greatest incentive to drive in suboptimal ways and engage in rent-seeking behavior.

We test this proposition using cross-sectional data from 1987 and 1992. These data contain truck-level information on OBC adoption and truck ownership. We find that OBC adoption leads to increased use of company drivers, particularly for hauls for which contracting problems are greatest: long hauls and hauls that use specialized trailers. This evidence supports the proposition and is our main empirical result.

We also examine relationships between trucks' fuel economy and $\mathrm{OBC}$ use. This provides a test for whether increased contractibility affects how drivers drive. We find that controlling for trucks' characteristics, how they are used, and where they are maintained, trucks with OBCs get better fuel economy than trucks without them. The fuel economy difference between company drivers with and without OBCs is greater than the difference between owner-operators with and without them. Furthermore, this is true only for long-haul drivers. The evidence thus supports our characterization of how OBCs affect drivers' behavior.

These results help to understand relationships between current waves of information technology (IT) diffusion and changes in firms' boundaries. As Hubbard (2000) points out, recent applications of IT — particularly networking applications_offer enhanced monitoring capabilities. These can increase contractibility. Our results indicate that when subcontracting decisions hinge on trade-offs between motivating care for productive assets and discouraging rent-seeking behavior, technology-enabled increases in contractibility will tend to lead to less outsourcing. If firms' 
boundaries are defined by asset ownership, then monitoring technologies that improve incentives will lead to larger firms.

This paper extends several strains of the empirical literature on organizations. Our emphasis on relationships between contractibility and ownership is similar to work that examines how outlet characteristics influence contractual form in franchising (Brickley and Dark (1987), Lafontaine (1992), Shepard (1993)). We are able to construct more powerful empirical tests than these earlier papers because we can base them on relationships between informational and organizational changes rather than levels. Our general result that monitoring and ownership are substitutes is consistent with findings from this literature. This paper is also related to a growing empirical literature that examines relationships between IT adoption and organizational form. (See Brynjolffson and Hitt (1997) and its citations.) Finally, the paper is related to recent work that investigates organizational issues in trucking (Hubbard (1999), Nickerson and Silverman (1999)), some of which focuses on technological issues (Chakraborty and Kazarosian (1999), Hubbard (2000)).

An outline of the rest of the paper follows. In section 2, we describe contracting problems in trucking, and how asset ownership and OBCs affect them. In section 3, we build a formal model that generates the hypotheses to be tested. In section 4 , we describe the empirical framework. In section 5 , we describe the data, present simple statistics that confirm the general patterns in the data, and show that data censoring problems are unlikely to drive estimation results. In section 6 , we present and interpret the estimation results. In section 7, we conclude.

\section{Production, Contractibility, and Asset Ownership in Trucking}

Carriers (for-hire trucking firms and trucking divisions of firms that are not trucking specialists, so-called "private fleets") haul goods for shippers (firms or divisions that want cargo moved from one place to another). When carriers receive orders, their dispatchers assign trucks and drivers to hauls. They may use company trucks and company drivers, or they may use owneroperators. In either case, they face several incentive problems in their agency relationship with their drivers. One is motivating drivers to complete hauls in a timely fashion; another is inducing them to drive in ways that neither cause undue wear and tear on trucks and their engines nor lead to higher than optimal accident rates. Arriving on time and driving in an optimal way are costly for drivers because they require effort and restrict drivers' ability to work at their own pace. 
Motivating drivers (whether company drivers or owner-operators) to arrive on time is relatively straightforward. Performance incentives work well. Carriers can obtain verified information regarding arrival times at low cost and reward drivers accordingly. Shippers generally notify carriers when trucks arrive unexpectedly late. Carriers reward drivers who consistently arrive on time with bonuses or good job assignments and punish those who consistently arrive late by firing them (if a company driver) or not hiring them again (if an owner-operator). Although factors outside of drivers' control affect whether drivers arrive on time, carriers often can verify whether traffic or delays in loading or unloading trucks cause trucks to be late. Agency costs associated with late arrivals are thus not large. ${ }^{3}$

Motivating company drivers to drive in an optimal fashion is more difficult because performance incentives are less efficient. Conditional on arriving on time, the cost of a haul is lower when drivers drive at a consistent rate than at a variable rate. Costs are increasing and convex in speed, both because of higher fuel consumption and greater depreciation of trucks' engines. Drivers may prefer to drive quickly then take longer breaks because it allows them to rest longer, visit friends, etc., and still arrive on time. Their ability to do so is particularly high on hauls with infrequent scheduled stops because there is more opportunity to make up time. Although one can base performance incentives on fuel use, trucks' condition, or accident rates, such measures are noisy indicators of how drivers drive. Fuel use and trucks' condition largely reflect how well trucks are maintained and accidents are rare events that are often caused by other drivers. Traditionally, how drivers drive has been non-contractible.

Asset ownership can motivate drivers to drive well. Owner-operators are residual claimants on the value of their truck and are responsible for maintenance and fuel purchases. They therefore internalize most of the costs associated with how they drive.

On the basis of the above description, it would seem that most hauls, especially long hauls, should be completed by owner-operators. However, another contracting problem plagues the agency relationship between carriers and drivers, and leads to high levels of company ownership of trucks, even for long hauls. Drivers must be motivated to accept hauls, and owner-operators have a greater

3. An exception to this is when contract enforcement issues inhibit carriers from punishing poor-performing drivers. Carriers sometimes allege this to be the case for union drivers. We do not emphasize such issues because the analysis is based primarily on the "truckload" sector, which is mostly not unionized. 
ability to hold up carriers and engage in rent-seeking behavior than do company drivers.

Hauls vary in their desirability to drivers. Those that take drivers into congested or dangerous areas are less desirable than those that do not. Hauls that involve layovers or empty ("deadhead") miles can be undesirable to long-haul drivers, whose compensation is generally output-based. ${ }^{4}$ Carriers negotiate with drivers to induce them to accept undesirable hauls. This negotiation usually involves a combination of moral suasion, promises to assign drivers desirable hauls in the future, and pecuniary compensation. Negotiation is pervasive because the timing of demand and availability of capacity are extremely difficult to forecast precisely outside of very short horizons. Carriers usually are not able to specify the exact hauls they will offer drivers more than a few hours in advance. Although arrangements between carriers and drivers usually extend over multiple periods, they are incomplete with respect to the specific hauls they cover.

Company drivers and owner-operators differ both in their leverage with carriers and in the extent they can improve their bargaining position. Company drivers can quit, but doing so leaves them with no equipment and whatever prospect they have for finding alternative employment. Owner-operators, on the other hand, have their trucks: they can access the spot market for hauls that exist in many regions. These markets, usually mediated by brokers, offer owner-operators and carriers access to hauls and play an important role in helping them fill long "backhauls" when return trips are not prearranged. Spot markets are generally thicker for hauls that use non-specialized equipment, and thinner for hauls that use specialized equipment. Accessing hauls for specialized equipment usually requires more costly search.

Truck ownership gives owner-operators the ability to access, and the incentive to explore, alternative shipments even while they are completing hauls for a particular carrier. Identifying alternative hauls improves their bargaining position with the carrier, and promises better terms for the hauls that they accept.

This description of carriers' relationship with their company drivers and owner-operators is consistent with characterizations related to us in interviews. Dispatchers often claim that they have more difficulty inducing owner-operators to accept hauls than company drivers. Unlike company

4. Long-haul drivers' compensation is generally based on based on either miles, loaded miles, or a fraction of the haul's revenues. This is true for both company drivers and owner-operators. 
drivers, owner-operators are considered to have the right to refuse hauls. Owner-operators are more "difficult to control" as a consequence. This is a frequently cited advantage of company ownership of trucks over driver ownership. ${ }^{5}$

The implication with respect to ownership patterns is the following: using owner-operators is costly in situations where they have incentives to invest in bargaining positions for subsequent hauls - that is, search for alternative hauls. Driver ownership of trucks mitigates incentive problems with how trucks are driven, but induces drivers to engage in rent-seeking behavior.

\section{Regulatory Issues and Control Rights Over Trucks}

Economic regulation of the trucking industry decreased dramatically during the late 1970s and early 1980s. It did not vanish, however. One provision that remains is that firms must obtain operating authority from the Federal government in order to legally haul goods between states. The cost of obtaining operating authority is not prohibitive but is high enough so that not all truck owners obtain it. Many owner-operators do not have operating authority, and therefore must operate under the authority of a carrier that does. ${ }^{6}$ Federal law requires owner-operators who operate under another carrier's authority to formally transfer control rights over their truck to the carrier during the period in which they are doing so. This is accomplished by an owner-operator lease. Some of these leases nominally cover long periods; six-month or one-year leases are not uncommon. In practice, most are open-ended.

On their face, long-term owner-operator leases appear to limit owner-operators' incentives for rent-seeking behavior: drivers cannot threaten to serve other customers if carriers have control rights over their truck. But the formal lease terms are misleading. Carriers do not deny owner-operators access to their trucks, even when drivers unilaterally terminate leases prematurely. The control right provisions in owner-operator leases are, for our intents and purposes, a legal fiction. They do not change the depiction of incentive conflicts above. ${ }^{7}$

5. See Maister (1980), Ouelett (1994), for example.

6. Most owner-operators have continuing relationships with one or more large carriers through whom they obtain hauls. Those without authority are required to formalize such relationships.

7. Thanks to Francine Lafontaine for useful discussions about owner-operator leases. See CFR 376.11 for the relevant regulations. 
This discussion gives rise to a more general contractual question: why do owner-operators have the right to take their truck with them whenever they quit? Contractual arrangements in which owner-operators agree not to use the truck for hauls other than the carrier's would lower drivers' rentseeking incentives while retaining their incentive to drive well. However, such arrangements would create new incentive problems: carriers could appropriate rents associated with the truck. One way they could do so is by offering drivers only hauls that are undesirable for the reasons given above. Not surprisingly, arrangements that give drivers residual claimancy but no control rights over their trucks are not optimal.

\section{On-Board Computers}

On-board computers (OBCs) appeared on the market during the mid-to-late 1980s. ${ }^{8}$ There are two classes of OBCs: trip recorders and electronic vehicle management systems (EVMS). As of 1992 , trip recorders cost about $\$ 500$. EVMS hardware cost $\$ 3,000-\$ 4,000$ to buy or about $\$ 150 /$ month to lease.

Trip recorders collect information about trucks' operation. They record when trucks are turned on and off, their speed over time, acceleration and deceleration patterns, fuel use, and variables related to engine performance. Dispatchers receive the information trip recorders collect when drivers return to their base; drivers give dispatchers a chart, floppy disk, or data cartridge with the data. These data are useful for two reasons. First, they provide carriers better measures of how drivers operate trucks. For example, carriers can tell when drivers speed or take long breaks. Second, they provide mechanics better information about trucks' engines. This enables them to diagnose and fix problems better. ${ }^{9}$

EVMS contain all trip recorders' capabilities, but have several additional features. First, they record trucks' location, sometimes via links to global positioning services. Second, they can transmit the information they collect to dispatchers in close to real time. Third, they allow dispatchers and drivers to send short text messages to each other. This feature enables dispatchers to initiate contact with drivers even when they are outside of radio range. Without EVMS, dispatchers generally have

8. See Hubbard (2000) for more details.

9. "On-Board Computers Enhance Driver Performance," Fleet Equipment, January 1989, describes in detail how carriers use trip recorders to monitor drivers and improve maintenance. 
to wait for long-haul drivers to call in to communicate with them. EVMS' additional capabilities make them useful for improving resource allocation (scheduling) decisions as well as incentives and maintenance. This distinction is emphasized in Hubbard (2000), which uses differences in adoption patterns to distinguish between situations where OBCs primarily improve incentives and primarily improve resource allocation decisions.

This paper investigates the organizational impact of the capabilities the two technologies share. Both technologies make how drivers operate trucks more contractible. Carriers using these technologies can observe not just arrival times, but whether drivers reach their destination by driving their trucks at a consistent pace. The next section presents a model of organizational form that we will then take to the data.

\section{Model}

We use a multi-tasking approach to model the choice of organizational form in trucking. There are two parties: a driver and a carrier. The driver faces effort choices on two tasks: driving well and rent seeking. The carrier has an order to haul cargo, and wants to induce a driver to drive a truck to fulfill the order. The value of the haul to the carrier is V, and the cost of the haul is M. M includes the wear-and-tear on the truck, and is a function of how well the driver drives. M is not contractible, since the amount of wear-and-tear due to any one haul is not evident. The profitability of the haul to the carrier is thus:

$$
\pi=\mathrm{V}-\mathrm{M}\left(\mathrm{e}_{1}\right)
$$

where $\mathrm{V}$ is the revenue from the haul, $\mathrm{e}_{1}$ is the non-contractible effort expended by the driver on good driving, and $M\left(e_{1}\right)$ is the cost of the haul; $M^{\prime}=-g_{1}$.

We will refer to $g_{1}$, the marginal effect of driver effort on cost, as the "scope for good driving." When $\mathrm{g}_{1}$ is large (for instance, on long hauls), the driver can do a lot to affect the cost of the haul, conditional on arriving on time; when $\mathrm{g}_{1}$ is small (for instance, on short hauls) he has little scope to affect the cost of the haul.

Drivers can also search for alternative hauls. The value of an alternative haul lined up by the driver is $\mathrm{P}\left(\mathrm{e}_{2}\right) . \mathrm{e}_{2}$ is the effort expended by the driver lining up alternatives: $\mathrm{P}^{\prime}=\mathrm{g}_{2}$. We assume that $\mathrm{V}$ is always greater than $\mathrm{P}$, so it is always efficient to accept the carrier's haul. But the presence of an 
alternative haul will give the driver more bargaining power with the carrier when it comes to haggling over the price on the backhaul. We refer to $\mathrm{g}_{2}$, the marginal product of driver effort on $\mathrm{P}$, as the "scope for rent seeking." $\mathrm{g}_{2}$ is large when the driver can greatly affect the value of his outside opportunities.

Both types of driver effort are costly. Driving well $\left(\mathrm{e}_{1}\right)$ is costly for two reasons: it demands more attention and it forces the driver to forgo opportunities for on-the-job consumption. Searching for outside opportunities $\left(\mathrm{e}_{2}\right)$ is costly because it requires time and energy. The driver's cost of effort is:

$$
\mathrm{C}\left(\mathrm{e}_{1}, \mathrm{e}_{2}\right)=\frac{e_{1}^{2}+e_{2}^{2}}{2}
$$

Conditional on an ownership structure, the driver chooses $\mathrm{e}_{1}$ and $\mathrm{e}_{2}$ to maximize his utility. We examine driver incentives under each ownership structure separately, then compare the surpluses that result to see which structure is more efficient.

Under company ownership of the truck, the driver bears none of the (non-contractible) wearand-tear costs of his driving, and so devotes no effort to good driving. $\mathrm{e}_{1}=0$. Furthermore, since he cannot capture any rents from lining up an alternative haul (since he does not have the right to use the truck) he will devote no effort to rent-seeking: $\mathrm{e}_{2}=0$.

Under driver ownership, however, the driver both bears the costs of his poor driving and has an incentive to engage in rent seeking. We assume that he bargains with the carrier, receiving half of the difference between what the haul is worth to the carrier and his alternative bid. ${ }^{10} \mathrm{He}$ thus stands to receive:

$$
\frac{V+P\left(e_{2}\right)}{2}-M\left(e_{1}\right)
$$

Driver utility is equal to his monetary reward, minus his cost of effort. Maximizing utility with respect to both $\mathrm{e}_{1}$ and $\mathrm{e}_{2}$ yields:

10. We do not model the bargain between the driver and the carrier under company ownership, because it has no effect on the driver's incentives. We could assume that the driver receives half of the revenue on each haul, or we could assume that he receives a fixed wage. 


$$
\mathrm{e}_{1}=\mathrm{g}_{1}, \mathrm{e}_{2}=\mathrm{g}_{2} / 2
$$

Under driver ownership, the driver exerts effort towards both good driving and rent seeking.

\section{Optimal Ownership Under Unobservable Driver Effort}

Under the assumption that it is always efficient to use the truck for the carrier's haul, total surplus is the sum of carrier profit and driver utility. Optimal ownership is that which maximizes total surplus. Surplus under company ownership is:

$$
S_{c}=V-M(0)-C(0,0),
$$

while surplus under driver ownership is:

$$
S_{o}=V-M\left(g_{1}\right)-C\left(g_{1}, \frac{g_{2}}{2}\right)
$$

Using the fact that $\mathrm{M}\left(\mathrm{e}_{1}\right)$ and $\mathrm{P}\left(\mathrm{e}_{2}\right)$ are linear in their arguments, it is easy to show that drivers should own their trucks whenever $2 \mathrm{~g}_{1}>\mathrm{g}_{2}$.

This model yields several predictions about when drivers should own trucks. One is that they should do so when the scope for good driving is large - that is, when $\mathrm{g}_{1}$ is large. As discussed above, this is more likely to be the case for long hauls than short hauls, since drivers can drive trucks very hard for many hours, and then consume the rest of the time it should have taken them however they choose.

The model also predicts that carriers should own trucks when the scope for rent-seeking is large-that is, when $\mathrm{g}_{2}$ is large. This is more likely to be the case when hauls use specialized equipment, since thick and efficient spot markets for hauls using standard equipment mean that there is little to be gained by investment in rent seeking by the driver. When the equipment is specialized, it is more likely that time and effort spent on searching out alternative hauls will yield a higherrevenue run that will give the driver more bargaining power with the carrier. ${ }^{11}$ Thus, owner-operators will be used more when hauls employ non-specialized trailers.

11. Of course, for very highly specialized equipment there may also be little gain from search, since there is virtually no chance of finding an alternative haul. We believe that this circumstance is not empirically relevant for our sample. 
This model thus yields the following predictions about truck ownership with non-contractible effort:

P1: $\quad$ Driver ownership should be more common in long-haul trucking than short-haul trucking.

P2: $\quad$ Driver ownership should be more common when hauls use non-specialized equipment (such as platforms and dry vans) than specialized equipment (such as tank trucks and refrigerated vans).

\section{Contractible Effort}

The model also can be used to analyze how ownership changes once good driving is made contractible through the use of OBCs. Suppose that the introduction of OBCs makes it possible to measure driver effort more accurately. This would allow the carrier to write an explicit incentive contract that leads the driver to drive in a value-maximizing way. Such a contract would peg $\mathrm{e}_{1}$ at (or near) first-best, $\mathrm{g}_{1}$.

With OBCs, company ownership generates surplus equal to:

$$
\mathrm{S}_{\mathrm{c}}^{\mathrm{OBC}}=\mathrm{V}-\mathrm{M}\left(\mathrm{g}_{1}\right)-\mathrm{C}\left(\mathrm{g}_{1}, 0\right)-\mathrm{d}
$$

where $\mathrm{d}$ is the per-period cost of $\mathrm{OBC}$ adoption.

In this model, OBCs generate no benefit when the driver owns the truck. Since owneroperators already drive optimally, technologies that improve their incentives to drive well yield no value. The model predicts that OBCs will never be used on driver-owned trucks; the surplus under driver ownership is the same as that shown in equation (5). Determining whether company drivers with OBCs will generate greater surplus than owner-operators involves comparing equations (5) and (6). Such a comparison shows that driver ownership yields greater surplus than company ownership with OBCs when:

$$
\mathrm{g}_{2}>2 \sqrt{2 \mathrm{~d}}
$$


Comparison of equations (4) and (6) also shows that company-owned trucks will adopt OBCs when:

$$
\mathrm{g}_{1}>\sqrt{2 \mathrm{~d}}
$$

These results taken together yield the pattern of adoption and ownership change summarized in Figure 1. It depicts the ownership patterns the model predicts for 1987 and 1992, before and after OBCs became available. In 1987, owner-operators are used whenever the scope for good driving is high relative to the scope for rent-seeking; that is, whenever $2 g_{1}>g_{2}$. In 1992 , this is no longer the case. It is optimal to utilize company drivers with OBCs whenever both the scope for good driving and the scope for rent-seeking are high. In the region where $2 g_{1}>g_{2}$ and $g_{2}>2 \sqrt{2 d}$, the northeast region in the figure, ownership changes. Hauls both adopt OBCs and move from owner-operators to company drivers. Ownership does not change in any of the other regions. This leads to our first proposition about the relationship between adoption and ownership.

\section{P3: $\quad$ OBC adoption should drive the incidence of driver ownership down.}

The model also predicts where adoption will lead to ownership changes and where it will not. The model predicts that adoption will only occur when both $g_{1}$ and $g_{2}$ are high. But this is because it focuses exclusively on OBCs' incentive-improving capabilities. Adoption will in fact occur when $\mathrm{g}_{1}$ or $\mathrm{g}_{2}$ are low because OBCs offer benefits other than incentive improvements. But when adoption takes place for maintenance- or coordination-related reasons, it should not affect truck ownership. Adoption should only lead to changes in asset ownership in the northeast region of Figure 1.

P4: $\quad$ OBC adoption should drive the incidence of driver ownership down more for long hauls using specialized trailers than for other hauls.

Testing P3 and P4 requires an empirical framework through which we can identify relationships between technological and organizational changes. The following section describes this. 


\section{Empirical Framework}

Following from above, let $S_{\text {io }}$ represent total surplus of haul $i$, if a driver owns the truck, and $\mathrm{S}_{\mathrm{ic}}$ represent total surplus of haul $\mathrm{i}$, if a carrier owns the truck. Specify these as:

$$
\begin{aligned}
& S_{i o}=X_{i} \beta_{o}+\varepsilon_{i o} \\
& S_{i c}=X_{i} \beta_{c}+\varepsilon_{i c}
\end{aligned}
$$

where $X_{i}$ is a vector depicting haul characteristics and whether OBCs are used. $\varepsilon_{\mathrm{io}}$ and $\varepsilon_{\mathrm{ic}}$ capture how haul characteristics not observed by the econometrician affect surplus when using owneroperators and company drivers, respectively.

Assuming that ownership choices are efficient, company drivers will be chosen if and only if $\mathrm{S}_{\mathrm{ic}}>\mathrm{S}_{\mathrm{io}}$. Assuming that $\varepsilon_{\mathrm{io}}$ and $\varepsilon_{\mathrm{co}}$ are i.i.d. type I extreme value, the probability the carrier owns the truck, conditional on $\mathrm{X}_{\mathrm{i}}$, is:

$$
P_{i c}=\frac{e^{X_{i}\left(\beta_{c}-\beta_{o}\right)}}{1+e^{X_{i}\left(\beta_{c}-\beta_{o}\right)}}=\frac{e^{X_{i} \beta}}{1+e^{X_{i} \beta}}=\Lambda\left(X_{i} \beta\right)
$$

If $\mathrm{E}\left(\mathrm{X}_{\mathrm{i}} \varepsilon_{\mathrm{io}}\right)=0$ and $\mathrm{E}\left(\mathrm{X}_{\mathrm{i}} \varepsilon_{\mathrm{ic}}\right)=0, \beta$ indicates how $\mathrm{X}_{\mathrm{i}}$ affects ownership. One then could estimate $\beta$ using cross-sectional data. But these orthogonality assumptions are not reasonable a priori because factors not observed by the econometrician may affect technology choice and truck ownership independently. For example, trucks used for unobservedly time-sensitive hauls may have OBCs to improve coordination and be owned by carriers to mitigate rent-seeking by drivers. Correlations between levels of OBC use and ownership shares therefore do not necessarily imply that adoption affects asset ownership.

With panel data, one could address this endogeneity problem by allowing for haul-specific fixed effects. The panel version of the above model is based on the equations:

$$
\begin{aligned}
& S_{i o t}=X_{i t} \beta_{o}+\phi_{i o}+\varepsilon_{i o t} \\
& S_{i c t}=X_{i t} \beta_{c}+\phi_{i c}+\varepsilon_{i c t}
\end{aligned}
$$

The likelihood function would be based on the expression:

$$
P_{i c t}=\Lambda\left(X_{i t} \beta+\phi_{i}\right)
$$


$\phi_{\mathrm{i}}$ would pick up time-invariant factors that affect the efficiency of driver ownership for a particular haul-for example, the haul's time-sensitivity. $\beta$ would be identified by relationships between changes in $\mathrm{X}_{\mathrm{i}}$ (for example, $\mathrm{OBC}$ adoption) and changes in governance. This would mitigate the endogeneity problem described above because if both IT use and ownership are affected by an omitted time-invariant variable, the fixed effects would account for this.

The data used in the analysis are not panel data: they are repeated cross-sections. They do not track individual trucks or hauls from period to period. Therefore, we base our analysis on observations of cohorts rather than trucks. These cohorts are at the level of product-trailer-distancestate; for example, an observation is "trucks based in California used to haul food long distances in refrigerated vans." Cohorts are defined narrowly in order to base them on as similar hauls as possible, given the data. Although we lose information by aggregating truck-level data up to the cohort level, doing so enables us to exploit the time dimension of the data and base tests on relationships between technological and organizational change rather than levels.

Our specification is a cohort analog of that described above. Let $\mathrm{s}_{\mathrm{crt}}$ be the share of company drivers in cohort $r$ at time $t$. We specify $s_{\text {crt }}$ and its analog $s_{\text {ort }}$ as:

$$
\begin{gathered}
s_{c r t}=\Lambda\left(X_{r t} \beta+\phi_{r}+\phi_{r t}\right) \\
s_{o r t}=1-\Lambda\left(X_{r t} \beta+\phi_{r}+\phi_{r t}\right)
\end{gathered}
$$

$\mathrm{X}_{\mathrm{rt}}$ are cohort means of variables observed by the econometrician. The most important variables in this vector are $\mathrm{OBC}$ adoption rates. The other terms are time-invariant and time-varying fixed effects. Note that (13) does not follow from aggregating the individual model. Although we use the same notation, the variables and parameters - in particular, $\beta$ - are not the same as those in the individual model.

From these expressions, we obtain:

$$
h_{r t}=\ln \left(s_{c r t} / s_{o r t}\right)=X_{i t} \beta+\phi_{r}+\phi_{r t}
$$

One can eliminate the cohort-specific fixed effects by taking first differences.

$$
h_{r t}-h_{r, t-1}=\left(X_{i t}-X_{i, t-1}\right) \beta+\eta_{r t}
$$


Here $\eta_{\mathrm{rt}}=\phi_{\mathrm{rt}}-\phi_{\mathrm{r}, \mathrm{t}-1}$. (15) is the base specification. The OBC coefficients in the parameter vector $\beta$ identify relationships between within-cohort adoption rates and changes in ownership shares. $\eta_{\mathrm{rt}}$ picks up omitted variables that affect changes in cohorts' ownership shares. If OBC adoption is orthogonal to this residual term, simple regression estimates of $\beta$ identify how adoption affects ownership. One can use these estimates to test propositions $\mathrm{P} 3$ and $\mathrm{P} 4$ from the previous section.

First-difference estimates greatly reduce concerns about endogeneity. But two issues remain. One is that omitted cohort-specific factors may affect adoption and ownership changes independently. For example, declines in the strength of local Teamsters unions may have affected both how much carriers adopted OBCs and how much they moved toward using company drivers between 1987 and 1992. If union strength declined at different rates across regions, this would generate cross-sectional correlations between adoption and ownership changes that would not reflect causal relationships. The other is that errors-in-variables issues arise when aggregating individual observations up to the cohort level. Deaton (1985) shows that if one estimates the sample analog to (15), there is an errors-in-variables problem with respect to the cohort-specific fixed effects. Firstdifferencing does not eliminate this source of error. It is captured in $\eta_{\mathrm{rt}}$ and may be correlated with the explanatory variables. We address this issue by estimating the model using instrumental variables, and discuss this in greater detail in section $6 .{ }^{12}$

Equations (14) and (15) are only well-defined if $\mathrm{s}_{\mathrm{crt}}$ and $\mathrm{s}_{\mathrm{ort}}$ are both greater than zero. When estimating these equations, one can only use cohorts for which the owner-operator and company driver shares are positive in both years. This raises the prospect of selection bias. Below we provide evidence that while selecting cohorts on this basis does mean that the analysis is based on cohorts with higher-than-average owner-operator shares, it likely does not affect estimates of $\beta$.

\section{Data}

The data are from the 1987 and 1992 Truck Inventory and Use Surveys (TIUS) (See Bureau of the Census $(1989,1995)$, Hubbard (2000).) The TIUS is a survey of the nation's trucking fleet that the Census takes every five years. The Census sends forms to the owners of a random sample of

12. We have also estimated the model dropping the smallest cohorts. In a previous version of this paper (Baker and Hubbard (1999)), we report estimates from specification that use only cohorts with five or more observations in each year and show that our results are robust. 
trucks. The survey asks owners questions about the characteristics and use of their truck. Characteristics include trucks' physical characteristics such as make and model year. They also include whether certain aftermarket equipment is installed-including whether and what class of OBCs are installed. Questions about use yield information on how far from home the truck was generally operated, the class of trailer to which it was generally attached, the class of products it generally hauled, and the state in which it was based. The survey also asks whether the truck was driven by an owner-operator or a company driver.

This paper uses observations of diesel-powered truck-tractors- the front halves of tractortrailer combinations. We eliminate observations of those that haul goods off-road, haul trash, are driven for less than 500 miles during the year, or have missing values for relevant variables. This leaves 19,308 observations for 1987 and 35,204 for 1992. The sample is larger for 1992 because the Census surveyed more trucks.

Table 1 contains owner-operator shares, by distance and year. In 1987, 14.1\% of tractortrailers were driven by their owners. ${ }^{13}$ The share is higher for long hauls than short hauls. This is consistent with P1. The right part of the table reports owner-operator shares for hauls using specialized and non-specialized trailers. Here and elsewhere in this paper, "non-specialized trailers" includes platforms and enclosed, non-refrigerated vans and "specialized trailers" includes all other trailer types. The most prevalent specialized trailers are refrigerated vans, dump trailers, and tank trucks. The owner-operator share is slightly higher for hauls using non-specialized trailers. This provides weak evidence in favor of P2. ${ }^{14}$ Owner-operators' share fell between 1987 and 1992 from $14.1 \%$ to $11.1 \%$ overall, decreasing within each distance and trailer category. The percentage point decline is greater for long hauls than short hauls, and for specialized than non-specialized trailers.

Table 2 reports OBC adoption rates, by organizational form and distance, for 1992. OBC adoption is negligible during 1987, and is treated as zero for that year throughout the paper. Table 2 indicates that some owner-operators adopt OBCs, presumably because of their maintenance and

13. Note that the sample contains trucks within both private and for-hire fleets. About half of the nation's trucktractors operate within private fleets. By definition, all trucks within private fleets are driven by company drivers. Also, the 1992 Survey contains more detailed distance categories than the 1987 Survey. We convert the five 1992 categories to the three 1987 ones when comparing the two years.

14. If one classifies dump trailers as non-specialized, the evidence for $\mathrm{P} 2$ is stronger. The difference between the non-specialized and specialized shares increases to $2.3 \%$. 
coordination benefits. Adoption is higher for trucks driven by company drivers, and increases with how far trucks operate from home. Almost 35\% of trucks used for hauls of 500 or more miles and operated by company drivers had either trip recorders or EVMS installed. Tables 1 and 2 thus indicate that $\mathrm{OBC}$ adoption coincided with ownership changes in the aggregate. Hauls in general moved from owner-operators to company drivers at the same time OBCs were beginning to diffuse. Ownership changes and $\mathrm{OBC}$ adoption were both greatest for long hauls.

The first column of Table 3 presents summary statistics for the 3676 cohorts in which at least one truck was observed in both years. ${ }^{15}$ Because cohorts are defined narrowly, on the average they are based on observations of very few trucks. As explained above, the main empirical analysis uses only cohorts with positive company driver and owner-operator shares in both years. Only 426 of the 3676 cohorts satisfy this criterion. The right two columns report summary statistics for the included and excluded cohorts. The included cohorts are based on more observations and have higher owneroperator shares than the excluded ones. The latter is because almost all of the excluded cohorts have no owner-operators in at least one of the two years. The included cohorts have larger changes in ownership and higher adoption rates than the excluded cohorts. The main empirical analysis is thus based on parts of the industry where the largest organizational and technological changes took place. This is because the included cohort subsample is disproportionately comprised of long haul trucks.

Table 4 examines relationships between technological and organizational change. We divide cohorts according to whether their owner-operator share increased, decreased, or stayed the same between 1987 and 1992 and compare OBC adoption rates for the three groups. The left panel uses all 3676 cohorts. On the average, cohorts where the owner-operator share decreased have an adoption rate of 0.22 . This is greater than the 0.20 adoption rate for those where the owner-operator share increased. The right panel uses only the included cohorts. The decreases and increases have average adoption rates of 0.25 and 0.22 , respectively. Adoption is thus correlated with changes in asset ownership. The similarity of this correlation in the two panels is evidence that relationships between

15. All calculations and estimates involving cohorts weight them by the number of observations within the cohort and weighting factors supplied by the Census that depict differences in sampling rates across states. The formula is $\left(\mathrm{n}_{\mathrm{r}, 87} * \mathrm{k}_{\mathrm{r}, 87}+\mathrm{n}_{\mathrm{r}, 92} * \mathrm{k}_{\mathrm{r}, 92}\right) / 2$, where $\mathrm{n}_{\mathrm{r}, \mathrm{t}}$ is the number of observations in cohort $\mathrm{r}$ and $\mathrm{k}_{\mathrm{r}, \mathrm{t}}$ is the average Census weighting factor in cohort $r$ in year $t$. The results in section 6 are robust to variations in weighting. 
adoption and organizational change for the included cohorts are representative of those of cohorts in general.

\section{Results}

The left panel of Table 5 contains results from estimating (14): the "levels" version of the model. In it, we report results from eight multivariate regressions. In each, the two dependent variables are the $\log$-odds ratios: $\ln \left(\mathrm{s}_{\mathrm{cr}, 1987} / \mathrm{s}_{\mathrm{or}, 1987}\right)$ and $\ln \left(\mathrm{s}_{\mathrm{cr}, 1992} / \mathrm{s}_{\text {or,1992 }}\right)$. In the top panel, we include OBC adoption rates, distance dummies, and $\ln$ (trailer density) as explanatory variables. The latter picks up differences in the thickness of the local trucking market. ${ }^{16}$ We restrict the coefficients on the explanatory variables to be the same in each year. OBC adoption rates only appear in the 1992 equation because adoption rates are zero by assumption in 1987. The four columns report the coefficient on OBC when we estimate the model using all included cohorts, short haul cohorts, medium haul cohorts, and long haul cohorts, respectively. In the bottom panel we include trip recorder and EVMS adoption rates separately.

The results indicate that cohorts with high OBC use also have high company driver shares. In the first column, the coefficient on OBC is positive and significant. Moving across the table, it is positive and significant for medium and long hauls, but not for short hauls. In the bottom of the table, the coefficients on trip recorder and EVMS are both positive and significant for medium and long hauls. This table indicates relationships between OBC use and ownership, but one is unable to determine whether this is because adoption caused ownership changes or because adoption took place for hauls for which company drivers were used in the first place.

The right panel presents results from analogous models that use 1992 truck-level data rather than cohorts. These are logits, where the dependent variable equals one if the truck was driven by a company driver and zero otherwise. Comparing these estimates to those in the left panel, the crosssectional relationships between $\mathrm{OBC}$ use and organizational form in our cohort sample are similar to those in the individual data. There is little evidence that selection bias is affecting our estimates of these relationships.

16. Trailer density is the number of trucks in the state that use the same trailer as the truck at hand, divided by the state's urbanized area. See Hubbard (1999) for details. 
Table 6 presents results from estimating equation (15). These are the first difference estimates. From the top panel, cohorts with high OBC adoption move disproportionately toward company ownership. Looking at the right side of the table, this is true only for long hauls. The difference between the long haul and both the short- and medium-haul coefficients is statistically significant, using a t-test of size 0.05. From the bottom panel, the trip recorder and EVMS coefficients are almost the same for long hauls. Neither are statistically significant for short or medium hauls. The estimates support P3 and part of P4: OBC adoption moves hauls toward company ownership, and does so most for the longest hauls.

These results produce two interesting contrasts. First, comparing the results in tables 5 and 6 , the medium haul coefficients lose statistical significance; those on $\mathrm{OBC}$ and trip recorder change sign as well. The positive and significant coefficients in table 5 therefore indicated that OBCs were adopted for medium hauls that used company drivers in the first place. In contrast, the coefficients on the long haul subsample remain positive and significant. Second, the trip recorder and EVMS coefficients are almost identical in the long haul specification in table 6 . This suggests that there is a relationship between ownership change and OBCs' incentive-improving features, but not their coordination-improving features. If OBCs' coordination-improving features influenced ownership, the coefficient on EVMS would differ from that on trip recorder.

The estimates suggest that OBC diffusion was an important factor in explaining the 4.5 percentage point decline in the long-haul owner-operator share between 1987 and 1992. The long haul estimate on $\mathrm{OBC}$ corresponds to a probability derivative of 0.13 , evaluated at sample means. The adoption rate of OBCs for long hauls is 0.26 in 1992. If the estimates reflect causal relationships, the product of the probability derivative and the adoption rate provides an estimate of the change in the owner-operator share that was due to OBC diffusion: 3.4 percentage points. This is about 75 percent of the decline in the owner-operator share.

Table 7 presents results when estimating (15) separately for non-specialized and specialized trailers. The point estimates indicate that the relationships between OBC adoption and organizational change are strongest for long hauls using specialized trailers. Looking at the right-most column, the point estimates are positive but not statistically significant for non-specialized trailers. They are positive, significant, and large for specialized trailers. However, the OBC coefficient is only 
statistically significantly larger for non-specialized than specialized trailers if one applies weak tests, because the standard errors are high. For example, the difference between the OBC coefficients for long haul trucks is 0.897 , with a standard error of 0.645 ; this is statistically significantly greater than zero using a t-test of size 0.15 , but not of smaller sizes. The estimates thus provide some support for $\mathrm{P} 4$, but this support is not strong.

In sum, relationships between OBC adoption and changes in truck ownership are strongest for hauls where the scope for good driving $\left(g_{1}\right)$ is high. There is also some evidence that they are stronger when drivers' incentive to engage in rent-seeking behavior $\left(\mathrm{g}_{2}\right)$ is high. OBCs are sometimes adopted where $\mathrm{g}_{1}$ and $\mathrm{g}_{2}$ are low, but there is little evidence that they induce ownership changes in such circumstances. These results are consistent with the proposition that OBCs affect asset ownership because they change the set of contractible variables, enabling carriers to encourage good driving without inviting rent-seeking behavior.

\section{First Differences, Fixed Effects}

We next present results from a series of specifications that add trailer, product, and state fixed effects in the first difference specifications. We do this for two reasons. First, it allows us to explore what is driving the results in table 6. If, for example, the parameter estimates become small and statistically insignificant when including a full set of trailer fixed effects, this would indicate that the results in table 6 are largely identified by systematic relationships between adoption and ownership changes at the trailer level. Second, it provides a guide for an identification strategy that lets us estimate (15) with instrumental variables. For example, if the coefficients on the trailer fixed effects are not jointly significant, then controlling for adoption rates, there is no evidence that there exist systematic differences in ownership changes across trailer types. Such a result would provide evidence in favor of an identification strategy that assumes that the unobserved factors that drove ownership changes during this period were independent across trailers.

Table 8 presents results using the long haul subsample from a series of estimates. The first column repeats the right column of table 6. The next three include trailer, product, and state fixed effects, respectively. The 12, 14, and 49 fixed effect coefficients in these three specifications are 
estimated but not reported. ${ }^{17}$ The last includes trailer, product, and state fixed effects. From the second column, the coefficients decrease somewhat when including trailer fixed effects- the trip recorder coefficient turns insignificant using a t-test of size 0.05 -but not much qualitatively changes. From the third column, they decrease more when including instead product fixed effects. Both the trip recorder and EVMS coefficients fall by $20-25 \%$ and turn insignificant. Part of the phenomena reported in table 6 is due to trailer and product-level effects, but most is not. From the fourth column, including state fixed effects makes the trip recorder coefficient fall by half. The trip recorder coefficient in table 6 is picking up relationships between trip recorder adoption and ownership changes at the state level. From the final column, including all three sets of fixed effects makes all the estimates noisy and not statistically significant.

The bottom of the table reports p-values for the hypothesis test that coefficients on the fixed effects are jointly equal to zero. One can reject this null only for the last two specifications. The trailer and product dummies have little explanatory power. In specifications not reported here, we found that this also was true for specifications that use all distances and medium hauls. (There are too few short haul observations to perform such tests.) The fact that the state dummies, but not the trailer and product dummies, have explanatory power indicates that the most compelling alternative interpretations of table 6 revolve around omitted variables that differ across regions rather than classes of hauls: for example, changes in local labor market conditions rather than changes in the time-sensitivity of certain classes of hauls. This makes the trailer and product dummies good candidates for instruments.

\section{GMM-IV Estimation}

Table 9 presents results from GMM estimation using trailer and product dummies as instruments. The second column uses only the trailer dummies. The point estimates remain positive, but all are very noisy - the standard errors are about twice as high as those in OLS estimation (reported in the first column). The third column uses only the product dummies. The point estimates on OBC and EVMS increase sharply. The OBC and EVMS coefficients are positive and significant using t-tests of size 0.05 ; the trip recorder coefficient is significant using a t-test of size 0.10 . The

17. There are actually 20 product categories. We combine several of the least common ones into a miscellaneous category in these specifications. 
fourth column uses both the product and the trailer dummies. The coefficients remain large and positive and the standard errors become about $20 \%$ smaller. The coefficients on OBC and trip recorder are significant using a test of size 0.05. That on EVMS is nearly the same as in the first column and is significant using a t-test of size 0.10 .

In specifications not shown, we fail to find any relationship between OBC adoption and ownership changes for short or medium hauls.

The GMM-IV estimates provide evidence that the results in table 6 reflect causal relationships. ${ }^{18}$ The 1.450 point estimate on OBC in the right column corresponds to a probability derivative of 0.18 . This, in turn, implies that OBC diffusion lowered the owner-operator share by 4.8 percentage points - about equal to the 4.5 percentage point actual decline in the owner-operator share. While our point estimates of the magnitudes are noisy, they suggest that much of the movement toward company drivers for long hauls was due to the diffusion of new monitoring technologies.

\section{Adoption and Driving Patterns}

In this subsection we investigate whether OBC use affects how company drivers drive. According to our model, one should expect OBC use to lead company drivers to operate trucks at more consistent speeds. If so, this should be manifested in better fuel economy. This section presents regression results in which we test whether, controlling for a host of truck characteristics, trucks with OBCs are more fuel efficient. There are two alternative interpretations if one finds that this is the case. One is that OBCs affect how drivers drive. The other is that OBCs supply information that helps mechanics maintain trucks better. To distinguish between these interpretations, we compare the relationship between OBC use and fuel economy for company drivers and owner-operators. Assuming that the maintenance value of $\mathrm{OBCs}$ is the same for company drivers and owner-operators, finding that it affects fuel economy more for company drivers is evidence of their incentiveimproving effect. ${ }^{19}$

18. Furthermore, the fact that the GMM-IV estimates are higher than the OLS estimates suggests that measurement error biases the OLS estimates toward zero: against finding such relationships.

19. Selection issues work against finding such a relationship. One would expect OBCs to be adopted where agency costs are the highest. Non-adopting company drivers probably drive better, on the average, than adopting ones would if they were not monitored. 
We run this regression on 1992 observations of individual trucks. The dependent variable is the truck's miles per gallon, reported by its owner in the TIUS. The main independent variables are interactions between dummies that indicate whether drivers own their trucks (one if driver ownership, zero otherwise) and whether OBCs are installed (one if installed, zero otherwise). We include many additional variables as controls. Control variables include dummy variables that indicate the truck's make, model year, engine size, the number of driving axles, and whether it has aerodynamic features. They also include variables that capture how the truck is used: how far from home it operates, whether it hauls single, double, or triple trailers, the average weight of the truck plus cargo, and whether it is attached to a refrigerated or specialized trailer. They include a set of dummy variables that indicate who maintains the truck: the driver, a garage, a trucking company, an equipment leasing firm, etc. Finally, we include the log of the truck's odometer reading to capture the effects of depreciation.

Table 11 reports results from four regressions. The owner-operator coefficient is negative and significant for short hauls, and statistically zero for medium and long hauls. There is no evidence that company drivers without OBCs drive less efficiently than owner-operators for medium and long hauls, and some evidence that they drive better for short hauls. ${ }^{20}$ The trip recorder and EVMS interactions indicate that medium- and long-haul trucks with OBCs get better fuel economy than those without them. There is no evidence that the trip recorder or EVMS coefficients are larger for company drivers than owner-operators for medium-haul trucks. But for long-haul trucks, the point estimate on the trip recorder coefficient for company drivers is more than twice as high as that for owner-operators. The difference is not significantly different from zero using a t-test of size 0.05 , but is when using a test of size 0.10. (The owner-operator estimate is noisy because so few owneroperators drive trucks with trip recorders.) On the average across long-haul trucks for which they were adopted, trip recorders' incentive effect improved fuel economy by at least 0.16 miles per gallon, assuming that selection biases the parameter estimates downward. ${ }^{21}$ Our estimates imply that this is about equal to aerodynamic hoods' effect on fuel economy. There is no difference in the

20. It is not clear, however, that driving better translates into higher fuel economy for short-hauls.

21. For a truck that travels 100,000 miles/year, a 0.16 improvement in MPG translates to a $\$ 620$ savings per year, assuming that fuel costs $\$ 1 /$ gallon. 
coefficients on the EVMS coefficients. The trip recorder contrast provides some evidence that company drivers with OBCs drive more cost-effectively than those without them. There is no evidence that EVMS use changes how drivers drive-perhaps because their primary purpose is improving dispatchers' scheduling decisions, not drivers' incentives.

\section{Conclusion}

This paper investigates what determines asset ownership in trucking; in particular, how contractibility affects whether drivers own the trucks they drive. We find that improved contracting (through the use of on-board computers) leads to more integrated asset ownership, by changing the set of decision rights - the residual control rights - that are allocated to the owner of the asset. Owner-operators are used for hauls where non-contractible decisions that affect trucks' value are important, but are used less once decisions become more contractible. We also provide evidence on truck operating performance (in the form of miles per gallon outcomes) that is consistent with the ownership results. Improvements in performance due to the installation of trip recorders are greater for company-owned drivers than for owner-operators, reflecting the improved incentives that the company drivers have after the adoption of OBCs.

More generally, this paper provides important support for the Grossman and Hart (1986) model of asset ownership. Owners-by definition-retain residual rights of control, and the equilibrium allocation of these residual rights is the one that induces the best incentives for maximizing the value of assets. This simple hypothesis has received little direct empirical testing; this paper provides such a test. The introduction of trip recorders on trucks does nothing to change the threat of hold-up, nor to reduce transaction costs among drivers, carriers, and shippers. Trip recorders are pure monitoring devices, serving only to make contractible a previously unmonitored set of actions. Indeed, trip recorders are almost irrelevant to the contractual relationship between carriers and owner-operators. Yet, by changing the efficiency of an alternative governance arrangement (company ownership), they reduce the relative efficiency of the owner-operator governance form.

The analysis in this paper may explain how contractibility affects firm boundaries in other contexts, especially those in which the care of valuable assets is important. Presumably the prevalence of independent contractors in the construction trades is importantly influenced by the 
requirement to provide incentives for proper operation and maintenance of equipment. The results in this paper suggest that changes in monitoring technology could change the industry structure in this sector. Such changes could similarly affect the professions. The prevalence of "owner-operators" in law and medicine is driven to a large degree by the need to vest in professionals the value of their reputational assets. It appears that changes in the ability of insurance companies and HMOs to monitor the actions of physicians is causing higher rates of vertical integration in medicine, leading doctors to become employees rather than independent contractors.

Innovations in information technology have led economists, technologists, and business people to theorize about how new informational capabilities will affect the boundaries of the firm. We test a theory concerning one of its capabilities: expanding the set of contractible variables. We find that this capability leads to less subcontracting. But changing information technology offers many other new capabilities, some of which improve resource allocation ("coordination") along with incentives. In future research, we plan to examine the organizational impact of some of these other capabilities, in particular how OBCs' coordination-enhancing capabilities affect shippers' make-orbuy decision. Results of this work will further improve our understanding of how information affects the organization of firms and markets. 


\section{References}

Alchian, Armen, and Harold Demsetz (1972). "Production, Information Costs, and Economic Organization," American Economic Review, 62, 777-795.

Baker, George, and Thomas N. Hubbard (1999). "Contractibility and Asset Ownership: On-Board Computers and Governance in the U.S. Trucking Industry," mimeo, July 1999.

Brickley, James A., and Fredrick H. Dark (1987). "The Choice of Organizational Form: The Case of Franchising," Journal of Financial Economics, 18, 401-420.

Brynjolffson, Erik, and Lorin Hitt (1997). "Information Technology and Organizational Design: Some Evidence from Micro Data," mimeo, Stanford University.

Bureau of the Census (1989). 1987 Census of Transportation: Truck Inventory and Use Survey. Washington, DC : Government Printing Office.

Bureau of the Census (1995). 1992 Census of Transportation: Truck Inventory and Use Survey. Washington, DC : Government Printing Office.

Chakraborty, Atreya and Mark Kazarosian (1999). "Product Differentiation and the Use of Information Technology: New Evidence from the Trucking Industry," mimeo, Brandeis University.

Coase, Ronald H. (1937). "The Nature of the Firm," Economica, 4, 386-405.

Deaton, Angus (1985). "Panel Data from Time Series of Cross-Sections," Journal of Econometrics, 30, 109-26.

Grossman, Sanford, and Oliver Hart (1986). "The Costs and Benefits of Ownership: A Theory of Vertical and Lateral Integration." Journal of Political Economy, 94, 691-719.

Hubbard, Thomas N. (1999). "How Wide Is the Scope of Hold-Up-Based Theories? Contractual Form and Market Thickness in Trucking," NBER Working Paper \#7347, September 1999.

Hubbard, Thomas N. (2000). "The Demand for Monitoring Technologies: The Case of Trucking," Quarterly Journal of Economics, forthcoming.

Lafontaine, Francine (1992). "Agency Theory and Franchising: Some Empirical Results," Rand Journal of Economics, 23, 263-283.

Maister, David H. (1980). Management of Owner-Operator Fleets. Lexington, MA: Lexington.

Milgrom, Paul, and John Roberts (1992). Economics, Organization, and Management. Englewood Cliffs, NJ : Prentice-Hall. 
Nickerson, Jack, and Brian S. Silverman (1999). "Why Aren't All Truck Drivers Owner-Operators? Asset Ownership and the Employment Relationship in Interstate For-Hire Trucking," mimeo, Harvard Business School.

Ouelett, Lawrence J. (1994). Pedal to the Metal: The Work Lives of Truckers. Philadelphia, PA : Temple.

Shepard, Andrea (1993). "Contractual Form, Retail Price, and Asset Characteristics in Gasoline Retailing,"Rand Journal of Economics, 24, 58-77.

Williamson, Oliver E. (1975). Markets and Hierarchies: Analysis and Antitrust Implications. New York: Free Press. 
Table 1

Owner-Operator Shares, 1987 and 1992

Owner-Operator Share, 1987
Owner-Operator Share, 1992

Change in Owner-Operator Share $\underline{\text { All Distances }}$

$14.1 \%$
$11.1 \%$
$-3.0 \%$

$14.1 \%$

$-3.0 \%$

$\leq 50$ Miles

50-200 Miles

$\underline{200+\text { Miles }}$

\section{$8.6 \%$}

$4.8 \%$

$11.5 \%$

$9.5 \%$

$-3.8 \%$

$19.8 \%$

$15.3 \%$

$-2.0 \%$
Specialized $\underline{\text { Trailers }}$

Non-Specialized
$13.8 \%$

$10.6 \%$

$-3.2 \%$
Trailers

$14.4 \%$

$11.7 \%$

$-2.7 \%$ 


\section{Table 2}

1992 On Board Computer Adoption Rates

Distance from Home Base (Miles)

$\underline{\leq 50} \quad \underline{50-100} \quad \underline{100-200} \quad \underline{200-500} \quad \underline{500_{+}}$

$O B C$

Owner-Operator

Company Driver

$3.7 \%$

$7.1 \%$

$3.1 \%$

$12.6 \%$

$4.0 \%$

$21.1 \%$

$7.0 \%$

$27.4 \%$

$9.8 \%$

Trip Recorder

Owner-Operator

Company Driver

$1.7 \%$

$4.3 \%$

$1.2 \%$

$0.9 \%$

$12.7 \%$

$2.3 \%$

$12.0 \%$

$2.4 \%$

$8.4 \%$

EVMS

Owner-Operator

Company Drive

$2.0 \%$

$2.8 \%$

$2.0 \%$

$3.1 \%$

$8.4 \%$

$4.8 \%$

$15.4 \%$

$7.4 \%$

$4.9 \%$

$26.5 \%$ 


\section{Table 3}

\section{Cohort Summary Statistics}

$\begin{array}{lccc} & \begin{array}{c}\text { All } \\ \text { Cohorts }\end{array} & \begin{array}{c}\text { All Included } \\ \text { Cohorts }\end{array} & \begin{array}{c}\text { All Excluded } \\ \text { Cohorts }\end{array} \\ \text { Cohorts } & 3676 & 426 & 3250 \\ \text { Observations/Cohort, 1987 } & 4.13 & 10.61 & 3.28 \\ \text { Observations/Cohort, 1992 } & 6.42 & 17.80 & 4.93 \\ \text { Owner-Operator Share, 1987 } & 0.14 & 0.27 & 0.08 \\ \text { Owner-Operator Share, 1992 } & 0.10 & 0.18 & 0.06 \\ \text { Change in O/O Share } & -0.04 & -0.09 & -0.02 \\ & & & \\ \text { OBC Adoption, 1992 } & 0.19 & 0.24 & 0.16 \\ \text { Trip Recorder Adoption, 1992 } & 0.09 & 0.10 & 0.08 \\ \text { EVMS Adoption, 1992 } & 0.10 & 0.14 & 0.08\end{array}$

Note: "Included" cohorts are those with owner-operator shares between zero and one in 1987 and 1992 Averages are computing using weights, where weight $=\left(\right.$ numobs $87^{*}$ expanf $87+$ numobs $92^{*}$ expanf92) $/ 2$ 


\section{Table 4}

\section{OBC Adoption by Sign of Ownership Share Change}

\begin{tabular}{|c|c|c|c|c|c|c|}
\hline & & All Cohorts & & & Iuded Coho & \\
\hline & & r-Operator & & & r-Operator & \\
\hline & Decreases & Increases & Same & Decreases & Increases & Same \\
\hline $\mathrm{N}$ & 821 & 683 & 2172 & 271 & 134 & 21 \\
\hline Mean Owner-Operator Share, 1987 & 0.33 & 0.06 & 0.01 & 0.31 & 0.17 & 0.24 \\
\hline Mean Owner-Operator Share, 1992 & 0.09 & 0.25 & 0.01 & 0.15 & 0.27 & 0.24 \\
\hline Mean OBC Adoption Rates, 1992 & 0.22 & 0.20 & 0.14 & 0.25 & 0.22 & 0.17 \\
\hline
\end{tabular}




\section{Table 5}

\section{Truck Ownership and OBC Adoption -- Levels Estimates}

\section{Product-Trailer-State-Distance Cohorts}

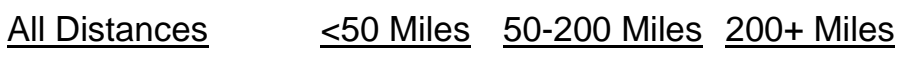

Individual Trucks, 1992 Data

$\underline{\text { All Distances }} \quad \leq 50$ Miles $\quad \underline{50-200 \text { Miles }} \underline{200+\text { Miles }}$

$\underline{\text { Variable }}$

OBC

$\begin{array}{llll}1.560 & -2.701 & 1.204 & 1.698\end{array}$

(0.389) (0.228)

1.272

(0.068)

0.029

(0.225)

1.367

1.331

$(0.189)$

(2.018)

$1.241 \quad 1.435$

$\begin{array}{lll}-4.817 & (0.511) & (0.367)\end{array}$

1.528

(0.119)

0.114

(0.300)

2.267

(0.320)

1.503

(0.298)

7.173

1.132

1.134

(0.081)

$-0.084$

0.700

(0.191)

1.253

(0.243)

(4.806)

(0.279)

123

265

33283

7998

11429

11941

Control variables (not shown) are distance from home dummies and In(trailer density).

The dependent variables in the left panel are In(company driver share/owner-operator share) in 1987 and 1992. The dependent variable in the right panel is a dummy variable that equals one if the truck is driven by a company driver and zero otherwise. The right panel uses only 1992 data. 


\section{Table 6}

\section{Truck Ownership and OBC Adoption -- First Difference Estimates}

Dependent Variable: In(cd share/o/o share)92 - In(cd share/o/o share)87

Cells are based on product-trailer-state-distance cohorts.

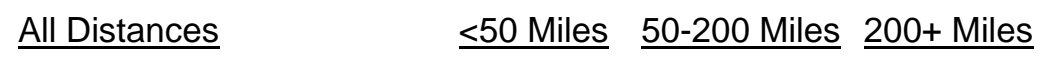

\begin{tabular}{lcccc} 
Variable & & & & \\
OBC & $\mathbf{0 . 6 3 0}$ & -2.697 & -0.612 & $\mathbf{1 . 0 2 4}$ \\
& $(\mathbf{0 . 2 5 2 )}$ & $(2.199)$ & $(0.517)$ & $\mathbf{( 0 . 3 2 0 )}$ \\
\hline Trip Recorder & 0.181 & & & \\
& $(0.380)$ & -4.465 & -0.899 & $\mathbf{1 . 0 8 2}$ \\
EVMS & $\mathbf{0 . 9 5 6}$ & $(2.377)$ & $(0.648)$ & $\mathbf{( 0 . 4 8 4 )}$ \\
& $(\mathbf{0 . 3 2 5 )}$ & 0.241 & 0.150 & $\mathbf{0 . 9 9 0}$ \\
& & $(5.645)$ & $(1.160)$ & $\mathbf{( 0 . 3 8 6 )}$ \\
$\mathrm{N}$ & 426 & & & \\
& & 38 & 123 & 265
\end{tabular}

Control variables (not shown) are distance from home dummies and In(trailer density). 
Table 7

Truck Ownership and OBC Adoption -- Trailer Subsamples

Dependent Variable: In(cd share/o/o share)92 - In(cd share/o/o share)87

Cells are based on product-trailer-state-distance cohorts.
$\underline{\text { Variable }}$
All Distances
$\leq 50$ Miles

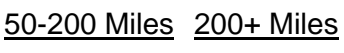

Specialized Trailers Only

\begin{tabular}{lcccc} 
OBC & 0.573 & -2.966 & -0.762 & $\mathbf{1 . 4 6 5}$ \\
& $(0.343)$ & $(2.403)$ & $(0.584)$ & $\mathbf{( 0 . 4 7 1 )}$ \\
\hline \multirow{2}{*}{ Trip Recorder } & -0.067 & -4.957 & $\mathbf{- 1 . 4 6 6}$ & $\mathbf{1 . 6 6 1}$ \\
& $(0.494)$ & $(2.562)$ & $\mathbf{( 0 . 7 1 4 )}$ & $\mathbf{( 0 . 6 8 6 )}$ \\
EVMS & $\mathbf{1 . 2 2 4}$ & 7.725 & 1.186 & $\mathbf{1 . 3 1 7}$ \\
& $(\mathbf{0 . 4 9 9 )}$ & $(6.321)$ & $(1.301)$ & $\mathbf{( 0 . 6 0 4 )}$ \\
& & & & \\
$\mathrm{N}$ & 229 & 33 & 76 & 120
\end{tabular}

Non-Specialized Trailers Only

\begin{tabular}{|c|c|c|c|c|}
\hline OBC & $\begin{array}{c}0.552 \\
(0.383)\end{array}$ & & $\begin{array}{c}0.458 \\
(1.122)\end{array}$ & $\begin{array}{c}0.567 \\
(0.443)\end{array}$ \\
\hline Trip Recorder & $\begin{array}{c}0.657 \\
(0.610)\end{array}$ & & $\begin{array}{c}2.039 \\
(1.473)\end{array}$ & $\begin{array}{c}0.497 \\
(0.699)\end{array}$ \\
\hline EVMS & $\begin{array}{c}0.499 \\
(0.451)\end{array}$ & & $\begin{array}{l}-3.192 \\
(2.512)\end{array}$ & $\begin{array}{c}0.603 \\
(0.523)\end{array}$ \\
\hline $\mathrm{N}$ & 197 & 5 & 47 & 145 \\
\hline
\end{tabular}

Control variables (not shown) are distance from home dummies and In(trailer density). Non-specialized trailers are platforms and enclosed non-refrigerated vans. 


\section{Table 8}

\section{Truck Ownership and OBC Adoption -- Fixed Effects}

\section{Long Haul Trucks Only}

\section{Dependent Variable: In(cd share/o/o share)92 - In(cd share/o/o share)87}

Cells are based on product-trailer-state-distance cohorts.

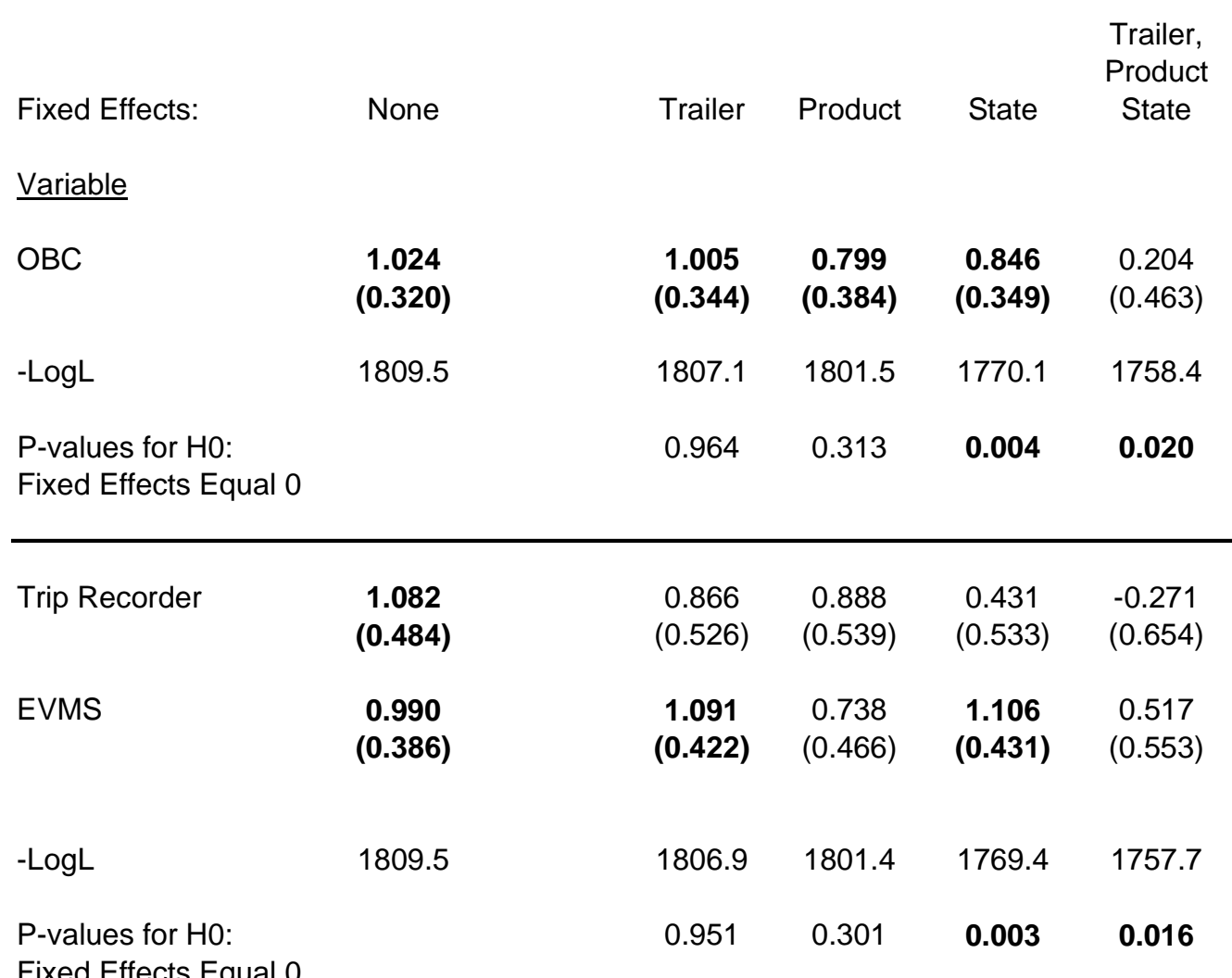

Control variables (not shown) are distance from home dummies and In(trailer density). 


\section{Table 9}

\section{Truck Ownership and OBC Adoption -- GMM-IV Estimates}

\section{Long Haul Trucks Only}

Dependent Variable: In(cd share/o/o share)92 - In(cd share/o/o share)87

Cells are based on product-trailer-state-distance cohorts.

\begin{tabular}{|c|c|c|c|c|}
\hline OBC & $\begin{array}{c}1.024 \\
(0.320)\end{array}$ & $\begin{array}{c}0.755 \\
(0.669)\end{array}$ & $\begin{array}{c}1.861 \\
(0.512)\end{array}$ & $\begin{array}{c}1.450 \\
(0.432)\end{array}$ \\
\hline \multicolumn{2}{|c|}{ Number of OID Conditions: } & 11 & 17 & 27 \\
\hline Trip Recorder & $\begin{array}{c}1.082 \\
(0.484)\end{array}$ & $\begin{array}{c}2.055 \\
(1.153)\end{array}$ & $\begin{array}{c}1.939 \\
(1.064)\end{array}$ & $\begin{array}{c}2.232 \\
(0.824)\end{array}$ \\
\hline EVMS & $\begin{array}{c}0.990 \\
(0.386)\end{array}$ & $\begin{array}{c}0.117 \\
(0.812)\end{array}$ & $\begin{array}{c}1.774 \\
(0.833)\end{array}$ & $\begin{array}{c}1.038 \\
(0.638)\end{array}$ \\
\hline \multicolumn{2}{|c|}{ Number of OID Conditions: } & 10 & 16 & 26 \\
\hline Instruments: & None & Trailers & Products & $\begin{array}{c}\text { Trailers and } \\
\text { Products }\end{array}$ \\
\hline
\end{tabular}

$\mathrm{N}=265$

Control variables (not shown) are distance from home dummies and In(trailer density). 


\section{Table 10}

\section{2: Fuel Economy, Vehicle Ownership, and Distance}

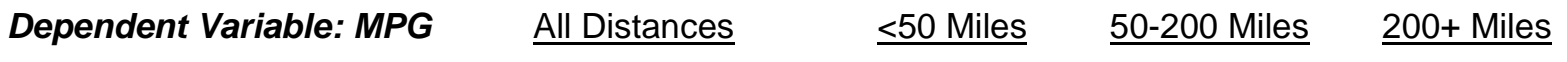

Variable

$\begin{array}{lcccc}\text { Owner-Operator } & \mathbf{- 0 . 0 4 2} & \mathbf{- 0 . 1 5 9} & -0.008 & -0.015 \\ & \mathbf{( 0 . 0 1 7 )} & \mathbf{( 0 . 0 6 4 )} & (0.033) & (0.019) \\ \text { TR*Owner-Operator } & 0.063 & -0.514 & 0.149 & 0.127 \\ & (0.096) & (0.330) & (0.265) & (0.091) \\ \text { TR*Company Driver } & \mathbf{0 . 1 8 6} & -0.011 & \mathbf{0 . 1 0 8} & \mathbf{0 . 2 8 9} \\ & \mathbf{( 0 . 0 1 9 )} & (0.067) & \mathbf{( 0 . 0 3 3 )} & \mathbf{( 0 . 0 2 1 )} \\ \text { EVMS*Owner-Operator } & \mathbf{0 . 1 8 4} & 0.299 & \mathbf{0 . 3 4 6} & \mathbf{0 . 1 4 6} \\ & \mathbf{( 0 . 0 6 4 )} & (0.343) & \mathbf{( 0 . 1 6 5 )} & \mathbf{( 0 . 0 5 9 )} \\ \text { EVMS*Company Driver } & \mathbf{0 . 1 1 5} & -0.060 & \mathbf{0 . 1 6 5} & \mathbf{0 . 1 2 6} \\ & \mathbf{( 0 . 0 1 9 )} & (0.084) & \mathbf{( 0 . 0 4 2 )} & \mathbf{( 0 . 0 1 9 )} \\ \text { R-squared } & 0.2102 & 0.1539 & 0.2411 & 0.2516 \\ \mathrm{~N} & 35203 & 8002 & 11647 & 15552\end{array}$

Regressions include controls for: distance from home, who maintains truck, refrigerated/specialized trailer, driving axles, vehicle make and model year, equipment dummies (such as for aerodynamic features), average weight, lifetime miles, and engine size. 
Figure 1

Asset Ownership and OBC Adoption

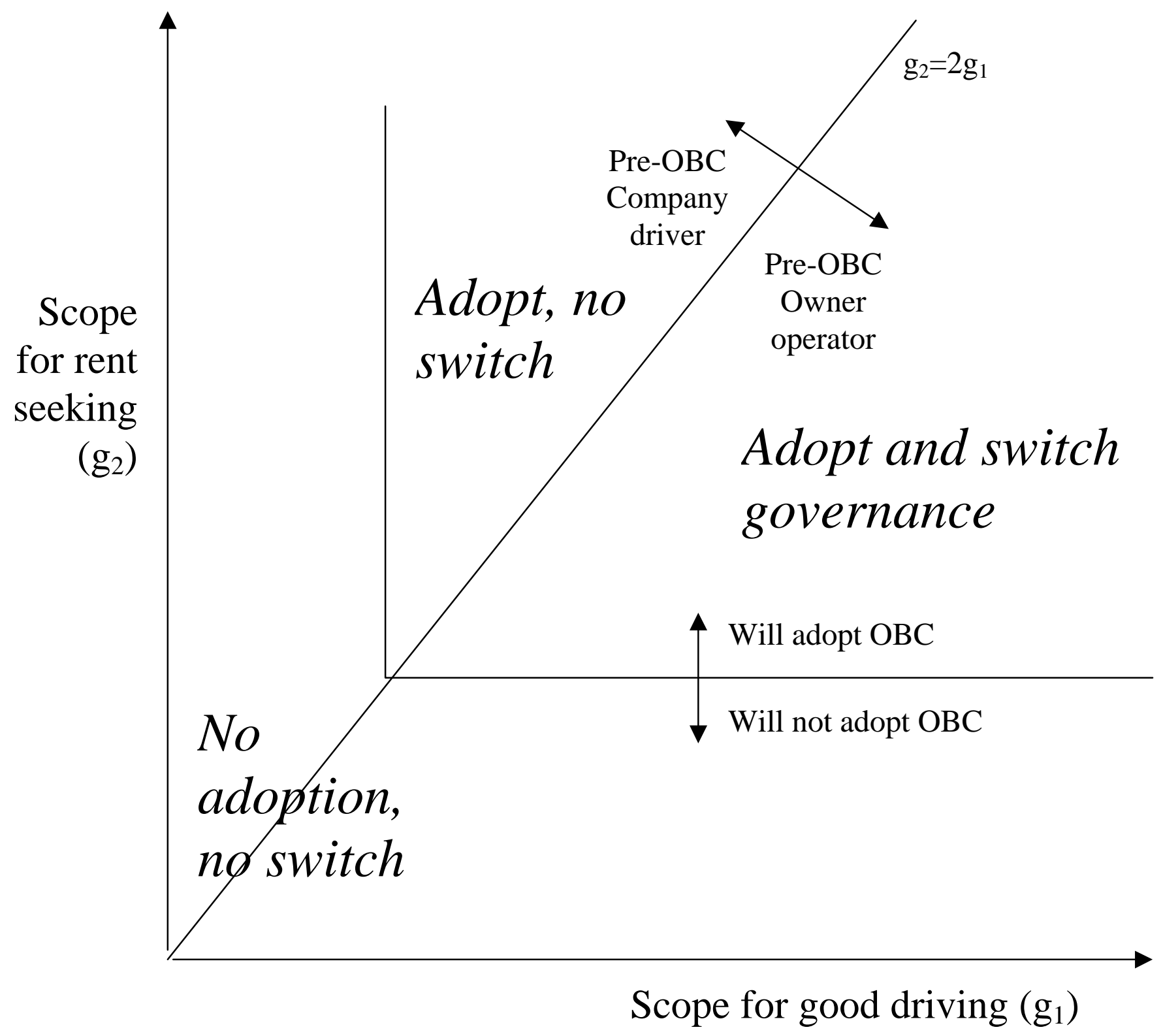

